\title{
The role of the habenula in drug addiction
}

\section{Kenia M. Velasquez, David L. Molfese and Ramiro Salas*}

Department of Psychiatry, Baylor College of Medicine, Houston, TX, USA

\section{Edited by:}

Masayuki Matsumoto, University of

Tsukuba, Japan

\section{Reviewed by:}

Ines Ibañez-Tallon,

Max-Delbrück-Center for Molecular Medicine, Germany

Thomas Jhou, Medical University of South Carolina, USA

\section{${ }^{*}$ Correspondence:}

\section{Ramiro Salas, Department of}

Psychiatry, Baylor College of

Medicine, One Baylor Plaza, Houston,

TX 77030, USA

e-mail:rsalas@bcm.edu
Interest in the habenula has greatly increased in recent years. The habenula is a small brain structure located posterior to the thalamus and adjacent to the third ventricle. Despite its small size, the habenula can be divided into medial habenula ( $\mathrm{MHb}$ ) and lateral habenula $(\mathrm{LHb})$ nuclei that are anatomically and transcriptionally distinct. The habenula receives inputs from the limbic system and basal ganglia primarily via the stria medullaris. The fasciculus retroflexus is the primary habenular output from the habenula to the midbrain and governs release of glutamate onto gabaergic cells in the rostromedial tegmental nucleus (RMTg) and onto the interpeduncular nucleus. The resulting GABA released from RMTg neurons inactivates dopaminergic cells in the ventral tegmental area/substantia nigra compacta. Through this process, the habenula controls dopamine levels in the striatum. Thus, the habenula plays a critical role in reward and reward-associated learning. The LHb also modulates serotonin levels and norepinephrine release, while the MHb modulates acetylcholine. The habenula is a critical crossroad that influences the brain's response to pain, stress, anxiety, sleep, and reward. Dysfunction of the habenula has been linked to depression, schizophrenia, and the effects of drugs of abuse. This review focuses on the possible relationships between the habenula and drug abuse.

Keywords: habenula, addiction, dependence, tobacco, nicotine, withdrawal

\section{THE HABENULA - GENERAL OVERVIEW}

Historically, the habenula has been neglected in the scientific literature, yet this small brain structure has increasingly been studied by neuroscientists and psychologists interested in pain, stress, anxiety, sleep, reward, depression, schizophrenia, and drug addiction. Habenula is Latin for "little rein," owing to this small structure's shape and location near the pineal gland and third ventricle. The habenula is divided into two anatomically and transcriptionally distinct structures: the medial habenula $(\mathrm{MHb})$ and lateral habenula (LHb; Klemm, 2004). The LHb plays a critical role in the brain's response to reward and thus has been more extensively studied than the MHb (Matsumoto and Hikosaka, 2007). In addition, the LHb has been linked to major depression (Sartorius et al., 2010), while the MHb has been linked to the effects of nicotine (Salas et al., 2009; Fowler et al., 2011; Frahm et al., 2011).

In terms of white matter connectivity, the stria medullaris is the primary habenular input and the fasciculus retroflexus is the primary output. Through the stria medullaris, the habenula receives inputs from the septum, hippocampus, ventral pallidum, lateral hypothalamus, globus pallidus, and other basal ganglia structures. The septum is the main input to the MHb, while the remaining structures project mainly to the LHb (Klemm, 2004). While the $\mathrm{MHb}$ projects to the $\mathrm{LHb}$, no connections from the $\mathrm{LHb}$ to the MHb have been described (Kim and Chang, 2005). Based on the input received, activity in the habenula is hypothesized to encode an organism reward state. If the reward state is positive,

Abbreviations: IPN, interpeduncular nucleus; VTA, ventral tegmental area; RMTg, rostromedial tegmental nucleus; nAChR, nicotinic acetylcholine receptor; GWAS, genome-wide association study; SNP, single nucleotide polymorphism; fMRI, functional magnetic resonance imaging; SNc, substantia nigra compacta. habenular activity is generally diminished. If the reward state is negative (e.g., during disappointing events) the habenular signal is enhanced. Information about reward state is then projected via the fasciculus retroflexus axon bundle to midbrain structures. The fasciculus retroflexus is divided into two concentric regions. The outer region originates in the $\mathrm{LHb}$ and projects to the rostromedial tegmental nucleus (RMTg). The RMTg, sometimes called the "tail" of the ventral tegmental area (VTA), is a small nucleus that contains mainly inhibitory GABAergic cells and ultimately controls activity in VTA/substantia nigra compacta (SNc), locus coeruleus and raphe nucleus. The inner region of the fasciculus retroflexus originates in the $\mathrm{MHb}$ and projects to the cholinoceptive interpeduncular nucleus (IPN; Herkenham and Nauta, 1977, 1979; Jhou et al., 2009a; Table 1).

Because of the role of the habenula in the modulation of dopamine, serotonin, norepinephrine, and acetylcholine, this region was the object of detailed study for a number of years (Herkenham and Nauta, 1977, 1979; Wang and Aghajanian, 1977; Cuello etal., 1978; Lisoprawski et al., 1980; Herkenham, 1981; Stern et al., 1981; Hamill et al., 1984). However, due to the small size of the habenula, the difficulty of doing non-invasive studies in humans, the lack of a clearly defined functional role (links to feeding behavior, pain sensitivity, anxiety, parental behavior, nicotine effects, and other behaviors were all demonstrated), and the lack of suitable pharmacological agents for habenula research, interest in the habenula began to taper off until 2007 when Matsumoto and Hikosaka published a seminal report on the habenula as a region associated with the signaling of negative prediction error events in the brain (Matsumoto and Hikosaka, 2007). The habenula was then linked to addiction through a series of rodent experiments and human genome-wide association studies 
Table 1 | The function and anatomic location of brain structures associated with the habenula.

\begin{tabular}{|c|c|c|c|}
\hline Structure & Anatomic location & Function & Reference \\
\hline Medial habenula (MHb) & $\begin{array}{l}\text { Above the thalamus at its posterior end close to } \\
\text { the midline. }\end{array}$ & Modulates acetylcholine & Klemm (2004) \\
\hline Lateral habenula (LHb) & $\begin{array}{l}\text { Above the thalamus at its posterior end close to } \\
\text { the midline, lateral to the } \mathrm{MHb} \text {. }\end{array}$ & Associated with negative emotions. & $\begin{array}{l}\text { Matsumoto and Hikosaka } \\
\text { (2007) }\end{array}$ \\
\hline Stria medullaris & $\begin{array}{l}\text { Located on the medial side of the thalamus; it's a } \\
\text { bundle of fibers that run along the roof of the third } \\
\text { ventricle to the thalamus and then terminates in } \\
\text { the habenula. }\end{array}$ & $\begin{array}{l}\text { Primary habenular input; projects to the } \\
\text { lateral habenula receives inputs from the } \\
\text { septum, hippocampus, ventral pallidum, } \\
\text { lateral hypothalamus, globus pallidus, and } \\
\text { other basal ganglia structure. }\end{array}$ & Klemm (2004) \\
\hline Fasciculus retroflexus & $\begin{array}{l}\text { Axon bundle divided into two concentric regions. } \\
\text { Outer region originates in the lateral habenula and } \\
\text { projects to the rostoromedial tegmental nucleus } \\
\text { (RMTg). Inner region originates in the } \mathrm{MHb} \text { and } \\
\text { projects to the cholinergic IPN. }\end{array}$ & $\begin{array}{l}\text { Primary habenular output; reward state is } \\
\text { relayed to the midbrain via the FR. }\end{array}$ & $\begin{array}{l}\text { Klemm (2004), Matsumoto } \\
\text { and Hikosaka (2007) }\end{array}$ \\
\hline $\begin{array}{l}\text { Interpeduncular nucleus } \\
\text { (IPN) }\end{array}$ & At the floor of the midbrain. & $\begin{array}{l}\text { The MHb projects to the IPN. Main } \\
\text { cholinergic center. }\end{array}$ & Klemm (2004) \\
\hline $\begin{array}{l}\text { Substantia nigra } \\
\text { compacta (SNc)/ventral } \\
\text { tegmental area (VTA) }\end{array}$ & Collection of neurons located in the midbrain. & $\begin{array}{l}\text { Where dopaminergic neurons are } \\
\text { located. Receive input from the LHb } \\
\text { through the RMTg. }\end{array}$ & $\begin{array}{l}\text { Matsumoto and Hikosaka } \\
\text { (2007), Jhou et al. (2009a) }\end{array}$ \\
\hline $\begin{array}{l}\text { Rostromedial tegmental } \\
\text { nucleus (RMTg) }\end{array}$ & $\begin{array}{l}\text { A small nucleus that contains mainly inhibitory } \\
\text { GABAergic cells, formerly called the "tail of the } \\
\text { VTA." }\end{array}$ & $\begin{array}{l}\text { Receives input from the LHb and projects } \\
\text { to midbrain dopamine neurons (VTA/SNc). }\end{array}$ & Jhou et al. (2009b) \\
\hline
\end{tabular}

(GWAS). These studies demonstrated that the nicotinic receptors expressed in the habenula are not only associated with tobacco addiction (Amos et al., 2008; Berrettini et al., 2008; Bierut et al., 2008; Thorgeirsson et al., 2008), but also with alcohol and cocaine addiction (Grucza et al., 2008; Wang et al., 2009). The dual role of the habenula in reward and addiction makes the structure an ideal target for understanding the effects of drugs of abuse on the brain. To date, most drug abuse-related research on the habenula has focused on nicotine, although the effects of cocaine, morphine, and other substances on the habenula have also been researched.

\section{PRECLINICAL WORK ON THE ROLE OF THE MEDIAL HABENULA ON NICOTINE EFFECTS}

The creation of nicotinic acetylcholine receptor (nAChR) subunit mutant mouse lines, both null mice (Picciotto et al., 1998; Xu et al., 1999a,b; Franceschini et al., 2002; Cui et al., 2003; Salas et al., 2003a,b, 2004b, 2009; Kedmi etal., 2004; Maskos et al., 2005) and gain-of-function mice (Broide et al., 2002; Tapper et al., 2004; Fonck et al., 2005), has allowed for the characterization of the effects of nicotine on different nAChR subunits (Table 2). Through this research, the $\mathrm{MHb}$ has emerged as a mediator of nicotine withdrawal symptoms after chronic nicotine treatment. The $\alpha 2, \alpha 5$, and $\beta 4$ subunits are involved in withdrawal (Salas et al., 2003b, 2004b, 2009) while the $\alpha 3, \alpha 5$, and $\beta 4$ subunits are necessary for nicotine-induced hypolocomotion (or sedation) and nicotine-induced seizures (Salas et al., 2003a, 2004a). The $\alpha 5$ subunit is involved in nicotine intake: $\alpha 5 \mathrm{KO}$ mice self-administer significantly more nicotine than wild type mice, suggesting that the $\alpha 5$ subunit is necessary for the aversive effects of nicotine (Fowler et al., 2011). In addition, the activity balance between the $\alpha 5$ and the $\beta 4$ subunits in the $\mathrm{MHb}$ has been shown to regulate aversion to nicotine (Frahm et al., 2011). Although, the molecular mechanisms mediating the effect of the $\mathrm{MHb}$ on nicotine withdrawal are not well understood, it was shown that the pacemaker activity of cholinergic (but not peptidergic) neurons in the MHb is critical for withdrawal (Gorlich et al., 2013). The $\beta 2$ subunit (usually expressed in combination with the $\alpha 4$ subunit) has been widely considered "the addiction subunit" in that nicotine self-administration in mice is dependent on the presence of this subunit (Picciotto et al., 1998). However, $\beta 2$ null mice exhibit normal nicotine withdrawal symptoms, suggesting that the effects of nicotine on $\beta 2$-containing nAChRs are not necessary for the appearance of withdrawal symptoms in nicotine-treated mice (Salas et al., 2004b). The $\alpha 2, \alpha 5$, and $\beta 4$ subunits have each been implicated in nicotine withdrawal and these subunits are expressed in a brain region-specific manner that highlights the $\mathrm{MHb}$. The $\alpha 5$ subunit is expressed in the MHb, IPN, some cortical areas, VTA, and in area CA1 of the hippocampus. This subunit is an "accessory" subunit that becomes functional when combined with other $\alpha$ - and $\beta$-subunits (Hsu et al., 2013). In addition to being expressed in the habenula, the $\alpha 3$ and $\beta 4$ subunits are expressed in the pineal gland and in mitral cells in the olfactory bulb; the $\alpha 3$ subunit 
Table 2 |The function and anatomic location of nicotinic acetylcholine receptors (nAChR) associated with the habenula.

\begin{tabular}{|c|c|c|c|}
\hline Receptors/subunit & Anatomic location & Function & Reference \\
\hline $\begin{array}{l}\text { Nicotinic } \\
\text { acetylcholine } \\
\text { receptors (nAChR) }\end{array}$ & $\begin{array}{l}\text { Ligand-gated ion channels formed by a } \\
\text { pentameric arrangement of alpha and beta } \\
\text { subunits to create distinct muscle and } \\
\text { neuronal receptors. }\end{array}$ & $\begin{array}{l}\text { Neuronal communication; converts } \\
\text { neurotransmitter binding in to membrane electrical } \\
\text { depolarization; binds the addictive drug nicotine. }\end{array}$ & Hogg et al. (2003) \\
\hline$\alpha 2$ & IPN, hippocampus. & $\begin{array}{l}\text { Involved in withdrawal symptoms after chronic } \\
\text { nicotine treatment. }\end{array}$ & $\begin{array}{l}\text { Salas et al. (2009), } \\
\text { Lotfipour et al. (2013) }\end{array}$ \\
\hline$\alpha 3$ & $\begin{array}{l}\text { Pineal gland, mitral cells in the olfactory bulb, } \\
\text { thalamus, } \mathrm{MHb} \text {. }\end{array}$ & $\begin{array}{l}\text { Necessary for nicotine-induced hypolocomotion } \\
\text { (or sedation) and nicotine-induced seizures. } \\
\text { Necessary for normal development of the } \\
\text { peripheral nervous system. }\end{array}$ & Xu et al. (1999a) \\
\hline$\alpha 4$ & Hippocampus, cortex, MHb, IPN. & Necessary for tolerance, reward and sensitization. & $\begin{array}{l}\text { Tapper etal. (2004), Salas } \\
\text { et al. (2004a) }\end{array}$ \\
\hline$\alpha 5$ & $\begin{array}{l}\text { Moderately expressed in the MHb. Also } \\
\text { expressed in the IPN, VTA, cerebral cortex and } \\
\text { in area CA1 of the hippocampus. }\end{array}$ & $\begin{array}{l}\text { Involved in withdrawal symptoms after chronic } \\
\text { nicotine treatment. }\end{array}$ & $\begin{array}{l}\text { Fowler etal. (2011), } \\
\text { Frahm etal. (2011), Salas } \\
\text { etal. (2009), Morel etal. } \\
\text { (2013), Bailey etal. (2010) }\end{array}$ \\
\hline$\alpha 6$ & VTA. Usually expressed with the $\beta 3$ subunit. & $\begin{array}{l}\text { Important for addiction, reward and dopaminergic } \\
\text { transmission. }\end{array}$ & $\begin{array}{l}\text { Wang et al. (2013), } \\
\text { Brunzell (2012) }\end{array}$ \\
\hline$\alpha 7$ & Hippocampus, cortex & $\begin{array}{l}\text { Forms homopentamers. May be involved in } \\
\text { schizophrenia-related behaviors. }\end{array}$ & $\begin{array}{l}\text { Freedman (2014), Young } \\
\text { and Geyer (2013) }\end{array}$ \\
\hline$\beta 2$ & $\begin{array}{l}\text { Ubiquitously expressed, usually with the } \alpha 4 \\
\text { subunit. }\end{array}$ & Essential for nicotine self-administration in mice. & Picciotto et al. (1998) \\
\hline$\beta 3$ & $\begin{array}{l}\text { MHb, VTA. Usually expressed with the } \alpha 6 \\
\text { subunit. }\end{array}$ & $\begin{array}{l}\text { Important for dopamine release, addiction, and } \\
\text { reward. }\end{array}$ & Cui et al. (2003) \\
\hline$\beta 4$ & $\begin{array}{l}\text { MHb, pineal gland and mitral cells in the } \\
\text { olfactory bulb. }\end{array}$ & Implicated in nicotine withdrawal. & Salas et al. (2004b) \\
\hline
\end{tabular}

is also expressed in the thalamus (Wada et al., 1989; Salas et al., 2003a, 2004a). Further evidence for a link between nicotine withdrawal and the habenula has been observed following injection of mecamylamine, a non-specific nAChR blocker, into the $\mathrm{MHb}$ of nicotine-treated mice. Mecamylamine injection precipitates somatic symptoms of withdrawal such as shakes and scratching, but only when injected into the MHb or IPN. In addition, $\beta 4, \alpha 5$, and $\alpha 2$ knockout mice show no nicotine withdrawal effects following mecamylamine injections, suggesting that the MHb/IPN circuit, with high levels of $\beta 4, \alpha 5$, and $\alpha 2$ subunit expression, is involved in the expression of behaviors related to nicotine withdrawal through neural mechanisms linked to these nAChRs (Salas et al., 2009). Consistent with a role for the $\alpha 2$ subunit in nicotine withdrawal, a recent study by Lotfipour et al. (2013) showed an increase in nicotine self-administration and withdrawal behavior (paw tremors, head shakes, backing, curls, grooming, scratching, chewing, cage scratching, head nodding, and jumping) in $\alpha 2$ -/ - mice. In a separate series of studies, Stanley Glick and his team examined the drug 18-methoxycoronaridine (18-MC), an antagonist of $\beta 4$-containing $\mathrm{nAChRs.} \mathrm{In} \mathrm{rodents,} \mathrm{microinjection}$ of 18 -MC into the $\mathrm{MHb}$ - but not in several other areas - blocks the effects of nicotine and cocaine (Glick et al., 2000, 2006; Maisonneuve and Glick, 2003; Taraschenko et al., 2007). In summary, the $\beta 2$ subunit-containing $\mathrm{nAChR}$ expressed in the VTA/SNc and in many other areas is essential for reward-related dopamine release in the striatum and is important for nicotinic self-administration in mice (Picciotto et al., 1998; Maskos et al., 2005). However, this subunit is not necessarily involved in nicotine withdrawal. In contrast, $\beta 4$ subunit-containing $\mathrm{nAChRs}$ expressed in the $\mathrm{MHb}$ and $\alpha 2$-containing nAChRs (highly expressed in the IPN) mediate the symptoms of nicotine withdrawal.

\section{GENOME WIDE ASSOCIATION STUDIES IN HUMANS}

Drug addiction has been linked to both environmental and genetic variables. Several studies have shown that susceptibility to drug addiction has a strong genetic component (Tsuang et al., 1998; Karkowski et al., 2000; Kendler et al., 2000). To discern the relative effects of genes and environment, a series of familial studies examined inheritance, twins, and adoption (Hall et al., 2013). These studies suggest a 30-50\% genetic component to drug addiction. Many genetic studies were based on a priori hypotheses about specific gene targets in each population. While those early studies 
were met with several successes, bias introduced by testing only a limited number of genes was inevitable. The development of new tools for examining genetic relationships across the entire genome GWAS opened a new era in genetic studies. In GWAS, a large number of genetic variants [typically hundreds of thousands or even millions of single nucleotide polymorphisms (SNPs)] are tested for association with a specific trait, such as smoking susceptibility, alcoholism, or drug addiction. Large samples (usually in the thousands) of control and affected populations are compared using rigorous corrections for multiple comparisons. Increased expression of specific gene variants within the affected population can thus be associated with the disease or condition being studied. It is important to note that these are association studies and not studies of causality (Amos, 2007).

Genome-wide association study studies of tobacco addiction have produced highly consistent results across laboratories with variants in the $\alpha 3, \alpha 5$, and $\beta 4 \mathrm{nAChRs}$ gene cluster associated with several measures of tobacco use and addiction (Amos et al., 2008; Berrettini et al., 2008; Bierut et al., 2008; Thorgeirsson et al., 2008). In particular, a significant link between the rs16969968 $\alpha 5$ SNP and smoking addiction was identified, and a meta-analysis yielded a significance of $p<10^{-71}$ (Bierut, 2011). Brain expression of the $\alpha 3, \alpha 5$, and $\beta 4 \mathrm{nAChRs}$ is highly restricted; the $\mathrm{MHb}$ is the only region that co-expresses the mRNA for all three of these subunits at either very high $(\alpha 3$ and $\beta 4)$ or moderate $(\alpha 5)$ levels. The IPN, the main output from the $\mathrm{MHb}$, is a primary site of $\alpha 5$ and $\beta 4 \mathrm{nAChR}$ subunit expression. Thus, GWAS data suggests that the habenula and associated regions expressing the $\alpha 5$ and $\beta 4 \mathrm{nAChR}$ subunits may play a role in tobacco addiction. Interestingly, the same SNPs that are associated with the risk of tobacco use are also associated with cocaine abuse (Grucza et al., 2008) and alcohol abuse (Wang et al., 2009). This suggests that the mechanism of addiction for different drugs of abuse shares overlapping genetic factors and anatomical brain regions. Given the role of the habenula in modulating reward and disappointment, it is not surprising that genes controlling habenular activity are also associated with drugs of abuse (Quick et al., 1999).

\section{THE LATERAL HABENULA AND THE NEGATIVE PREDICTION ERROR}

Drugs of abuse increase dopamine levels in the striatum. Since dopamine levels have been related to reward, it is believed that drug-induced increases in dopamine are important for the abuse potential of drugs (Di Chiara and Imperato, 1988). Activity of dopaminergic cells in the VTA/SNc is of critical importance for reward signaling and in addictive behaviors. Indeed, early work in primates showed that dopaminergic cells in the VTA/SNc are activated by oral delivery of sweet juice (Montague et al., 1996; Schultz et al., 1997). However, more recent experiments have shown that the role of dopamine in reward is more complex than simple stimulus-response. Monkeys that learn to associate juice reward with a predictive cue, such as a flash of light, shift the spike of dopaminergic activity to the cue. Following cue-juice association, the juice no longer induces dopaminergic activity, yet withholding of the expected juice reward causes dopamine levels to drop. This suggests that dopamine may actually signal reward prediction, rather than reward itself, and a negative prediction error or “disappointment" following lack of reward (Montague et al., 1996; Schultz et al., 1997). The decrease in dopaminergic activity is analogous to a negative prediction error and has been hypothesized to play a role in learning from mistakes. Only recently has the neural signal responsible for this drop in dopamine release been localized to the LHb (Matsumoto and Hikosaka, 2007). In their seminal 2007 work, Matsumoto and Hikosaka trained monkeys to perform lateral saccadic eye movements. A saccade to one side predicted juice delivery while saccades to the other side did not predict juice reward. By altering the probability of juice reward, Matsumoto and Hikosaka were able to create conditions of both unexpected reward and of reward disappointment when the juice was expected, but not delivered. They demonstrated that activity of neurons in the LHb increased following negative prediction error events (lack of expected reward) and decreased following unexpected juice reward. It follows that the habenula is activated by negative events. This activation decreases downstream dopaminergic activity through GABAergic inhibition of brain structures receiving habenular inputs and results in negative affect (Matsumoto and Hikosaka, 2007). In humans, the decreased reward experienced by chronic drug users may result from increased habenular activity and the resulting inhibition of dopamine in the VTA/SNc.

\section{HABENULAR CONTROL OF DOPAMINE, SEROTONIN, AND NOREPINEPHRINE}

Neural signals from the LHb ultimately affect the VTA/SNc, the raphe nucleus, and the locus coeruleus (both directly and indirectly through the RMTg; Klemm, 2004; Balcita-Pedicino et al., 2011). The VTA/SNc is the most studied downstream habenular target, although both the raphe nucleus and locus coeruleus also receive strong signals from the LHb (Hikosaka et al., 2008). Given the role these structures play in the regulation of dopamine, serotonin, and norepinephrine, the LHb likely modulates neurotransmitter release in those three systems. Thus, it is not entirely surprising that habenular activity has been linked to several seemingly unrelated behaviors and disease conditions. For example, the habenula has been linked to stress-enhanced acoustic startle, probably via effects on the locus coeruleus (Heldt and Ressler, 2006). The LHb has been linked to maternal feeding and sexual behaviors (Klemm, 2004). The LHb has also been linked to major depressive disorder (MDD) in both preclinical and clinical research. In mice, learned helplessness (an animal model for studying depression-like symptoms) results in potentiation of LHb outputs, suggesting an increase in negative neural signaling (Li et al., 2011). Using cytochrome oxidase histochemistry, a metabolic marker, both the MHb and the LHb have been implicated in learned helplessness and depressive behavior in rats reared to exhibit these traits (Shumake et al., 2004). In humans, the severity of depression symptoms in patients correlated with the level of coupling between the habenula and the raphe nucleus: The stronger the link between these brain structures, the more severe the depression symptoms after a tryptophane-free diet was given to depression patients in remission to acutely precipitate depression symptoms (Morris et al., 1999). The link between habenular activity and MDD was further demonstrated in a treatment-resistant MDD patient who responded to deep brain stimulation of the $\mathrm{LHb}$ when other treatments for depression were 
shown to be ineffective (Sartorius et al., 2010). Taken together, these findings suggest that MDD may result from a combination of habenular hyperactivity that disrupts dopaminergic and serotonergic signaling following negative or disappointing events along with decreased dopaminergic activity following positive events.

\section{THE ROLE OF THE HABENULA IN COCAINE DEPENDENCE}

Using cocaine reinstatement protocols it was demonstrated that high reinstatement rats and mice show higher c-fos activity than low reinstatement animals (Brown et al., 2010; James et al., 2011). While cocaine is initially rewarding, cocaine aversion usually develops about $15 \mathrm{~min}$ after injection (Ettenberg et al., 1999). Signals from the LHb inhibit dopaminergic neurons reducing the dopaminergic reward signal which can account for the aversive effects of cocaine (Jhou et al., 2013).

A study by Maroteaux and Mameli (2012) showed the synaptic plasticity of LHb neurons in mice, when exposed to cocaine. They demonstrated that exposure to cocaine selectively potentiates alpha-amino-3-hydroxy-5-methyl-4-isoxazolepropionic acid receptor (AMPAR)-mediated transmission in LHb neurons projecting to the RMTg but not to the VTA. They stereotaxically injected green and red fluorobeads in the VTA and RMTg and then examined if cocaine affected excitatory synaptic transmission on the LHb neurons. These mice were injected with cocaine and saline for two consecutive days. They found that cocaine exposure strengthens AMPAR-mediated synaptic transmission but only in $\mathrm{LHb}$ to RMTg neurons. Their data suggests that the composition of the synaptic AMPARs in LHb to RMTg neurons was not significantly changed by the cocaine. A residual current at positive potentials was detected, suggesting that excitatory synapses onto LHb neurons likely contain GluA2-lacking and GluA2-containing AMPARs. In sum, they offer evidence for a synaptic potentiation in the LHb that could represent an important mechanism involved in the formation of drug-associated memories (Maroteaux and Mameli, 2012).

\section{THE ROLE OF THE HABENULA IN MORPHINE DEPENDENCE}

The habenula has also been implicated in morphine addiction, although the exact relationship between habenular activity and morphine is inconsistent across studies. Chronic morphine administration (escalating doses of 20,40,60, 80, 100, and $100 \mathrm{mg} / \mathrm{kg}$ three times per day) leads to a reduction in acetylcholinesterase (AChE) activity in the MHb (Neugebauer et al., 2013). During morphine withdrawal, AChE activity in MHb returns to baseline, suggesting a homeostatic balance. However, a second study using higher doses of morphine $(450 \mathrm{mg} / \mathrm{kg})$ administered for a longer period of time (15 days), showed increased AChE activity in the habenula (Mohanakumar and Sood, 1983).

Unlike cocaine, which increases Fos protein expression in the habenula (Brown et al., 2010; James et al., 2011), chronic morphine exposure reduces c-fos activity in the MHb (Neugebauer et al., 2013). Morphine withdrawal has also been shown to increase glucose metabolism in a number of limbic and thalamic regions, including the MHb (Kimes et al., 1990). Again suggestive of a homeostatic balancing mechanism, morphine withdrawal elevates
Fos protein levels in the LHb. Somewhat surprisingly, similar patterns of c-fos positive cell activation have been reported in animals seeking sucrose following abstinence (Madsen et al., 2012).

\section{THE FASCICULUS RETROFLEXUS DEGENERATES FOLLOWING TREATMENT WITH DRUGS OF ABUSE}

The rodent fasciculus retroflexus has been shown to degenerate following chronic exposure to stimulants such as D-amphetamine, methamphetamine, MDMA, cocaine, and nicotine. The fasciculus retroflexus nerve bundle connects the habenula to its main targets, the IPN and RMTg. Interestingly, nicotine treatment prompts cell death and axonal degeneration in the central region of the fasciculus (axons coming from the $\mathrm{MHb}$ ) while other drugs of abuse prompted neurodegeneration in the external region (axons coming from the LHb; Ellison, 2002; Ciani et al., 2005). A recent study of fasciculus retroflexus integrity in rats showed neurodegeneration of the habenular efferent following increased cocaine self-administration, indicating a reduction in LHb to midbrain connectivity (Lax et al., 2013). Overall, the fasciculus retroflexus appears to be a "weak link" in the brain's reward circuitry, one that is particularly susceptible to drugs of abuse (Ellison, 2002). The cause of fasciculus retroflexus degeneration remains unclear, however, multiple drugs of abuse may affect this pathway in that the habenula is activated during cocaine, morphine, and nicotine drug seeking behavior and during drug re-instatement following abstinence (Brown et al., 2010; James et al., 2011).

\section{8-MC, AN ANTAGONIST OF $\beta$ 4-CONTAINING nAChR, DECREASES SEVERAL EFFECTS OF ABUSED DRUGS}

Ibogaine, an extract from the African shrub Tabermanthe iboga, is a hallucinatory alkaloid used in African spiritual ceremonies. In the 1960s, ibogaine was used to treat several forms of addiction through apparent effects on the cholinergic and glutamatergic neurotransmitter systems. In rodents, ibogaine was shown to reduce self-administration of cocaine (Cappendijk and Dzoljic, 1993), alcohol (Rezvani et al., 1995), and morphine (Glick et al., 1991). However, because of the severe side-effects associated with ibogaine (e.g., headaches, nausea, hallucinations), the alkaloid has been banned in the USA and other countries. Ibogaine drug derivatives, such as 18-MC, however, have been created in an attempt to develop medications to treat drug addiction. The 18-MC compound has been shown to effectively block cravings and withdrawal and to decrease self-administration of morphine, cocaine, and nicotine in laboratory animals (Glick et al., 2000). The drug does not affect water consumption, unlike the naturally occurring Ibogaine. Furthermore, the effectiveness of 18-MC increases with repeated treatments and reduces the overall intensity of morphine withdrawal symptoms in rats (Glick et al., 2000). The mechanism of action for 18-MC and the site of action remain unclear. While direct injection of 18-MC into the locus coeruleus reduces symptoms of morphine withdrawal, direct injection into the $\mathrm{MHb}$ has mixed effects. Low doses of $18-\mathrm{MC}$ in the habenula reduce teeth chattering and weight loss while higher doses increase teeth chattering and reduce burying behaviors during morphine withdrawal (Panchal et al., 2005). 18-MC also blocks the acquisition of conditioned place preference (CPP) for cocaine, 
but enhances the reinstatement of cocaine-seeking behavior following extinction (McCallum and Glick, 2009). 18-MC does not affect glutamate receptors, but retains antagonistic activity toward the highly expressed $\beta 4$-containing nAChRs in the MHb and IPN (Glick et al., 2006). Additionally, 18-MC affects dopaminergic activity, which is regulated by the LHb. Consequently, targeting of $\beta 4$-containing $\mathrm{nAChRs}$ in the $\mathrm{MHb}$ could prove therapeutic to the treatment of nicotine, cocaine, morphine, alcohol, and methamphetamine addiction.

\section{VARENICLINE AFFECTS DEPENDENCE ON DRUGS OF ABUSE}

Varenicline is a partial agonist of nAChRs and is approved by the FDA for use in tobacco quitting therapies (Coe et al., 2005). The effects of varenicline on tobacco addiction are well studied, but it is becoming evident that varenicline may also be effective in the treatment of other drugs of abuse. Varenicline effectively weakens cocaine reinstatement in small doses, but increases cocaine reinstatement in higher doses even as it decreases self-administration (Guillem and Peoples, 2010). In rodent studies of varenicline and alcohol abuse, the drug reduced ethanol seeking behavior at the same doses previously shown to reduce nicotine-seeking behavior, but did not alter sucrose-seeking behavior in self-administration experiments. In mice, voluntary ethanol consumption was also decreased, but not water consumption (Steensland et al., 2007). These results suggest that varenicline may be an effective treatment not only for tobacco but also for other drugs of abuse (Crunelle et al., 2010). Although most of the literature points to $\alpha 4 \beta 2$-containing $\mathrm{nAChR}$ as the relevant target the $\alpha 3 \beta 4$ subunit receptor has also been implicated in addiction and the $\beta 4$ subunit was recently linked to varenicline's reduction of ethanol consumption (Chatterjee et al., 2011). Mihalak et al. (2006) have shown that varenicline is a partial agonist of both $\alpha 4 \beta 2$ and $\alpha 3 \beta 4$ nAChRs. Thus, it is likely that at least some of the effects of varenicline on drug abuse are mediated by the habenula where these receptors are expressed at high concentration.

\section{THE MEDIAL AND THE LATERAL HABENULA}

The role of the MHb in drug addiction and abuse has been demonstrated through rodent studies of nicotinic receptors as well as suggested by GWAS studies in humans. A role for the LHb in addiction is suggested by negative prediction error studies (Matsumoto and Hikosaka, 2007; Salas et al., 2010), deep brain stimulation in rodents (Lax et al., 2013), and drug-induced fasciculus retroflexus degeneration in rodents (Ellison, 1992, 2002). While it is possible that the $\mathrm{MHb}$ and the $\mathrm{LHb}$ regulate distinct mechanisms of drug dependence and abuse, we believe that this is not necessarily the case. McCallum et al. (2012) recently showed that blockade of $\beta 4$ subunit-containing $\mathrm{nAChRs}$ in the $\mathrm{MHb}$ directly affects mesolimbic dopamine. Microinjections of 18-MC or AuIB (both preferential $\beta 4$ antagonists) into the $\mathrm{MHb}$ prevented nicotineinduced increases in nucleus accumbens (NAcc) dopamine. Thus, there must be a connection between the $\mathrm{MHb}$ and NAcc dopamine levels (McCallum et al., 2012). The MHb may regulate dopamine in striatal regions through several mechanisms, although two candidate pathways appear most likely. First, the IPN is the primary target of the $\mathrm{MHb}$ and projects directly to dopaminergic areas, making it possible that activity in the MHb influences dopamine levels in the striatum independent of LHb activity (Groenewegen et al., 1986; Klemm, 2004). Second, direct connections from the $\mathrm{MHb}$ to the $\mathrm{LHb}$ have also been reported, but not in the opposite direction, making it possible that one of the functions of the $\mathrm{MHb}$ is to provide additional input to the LHb (Kim and Chang, 2005). The mechanisms by which these structures may modulate dopamine availability in the striatum are unknown at this time.

\section{ELECTRICAL STIMULATION IN THE LATERAL HABENULA REDUCES COCAINE-SEEKING BEHAVIOR}

Deep brain stimulation is an effective treatment for several neurological diseases and conditions, including Parkinson's disease and depression (Mayberg, 2009; Callesen et al., 2013). In rodent studies, electrical stimulation of the LHb reduced cocaine cravings, self-administration, and reinstatement while improving extinction. Damage to the $\mathrm{LHb}$ increased cocaine-seeking behavior, suggesting that this behavior may result from a weakening of cocaine-induced glutamatergic inputs to the VTA (Friedman et al., 2010). Since cocaine treatment causes degeneration of the fasciculus retroflexus (Ellison, 1992), it is important to know the status of the fasciculus retroflexus in human cocaine users before attempting to use deep brain stimulation as a possible therapy for cocaine abuse.

\section{INSIGHT FROM HUMAN FMRI STUDIES}

Most of what we know about the habenula comes from rodent and monkey models. In humans, study of the habenula has been hampered by its small size. In the first functional magnetic resonance imaging (fMRI) report focusing on the habenula, the authors asked human participants to guess which of two visual stimuli would reach a target first. The task difficulty was modulated so that all participants would commit a similar number of errors and receive the same degree of positive and negative feedback. Negative feedback activated the habenula (Ullsperger and von Cramon, 2003). Using a similar strategy, Shepard et al. (2006) reported that schizophrenic patients lack habenular activation following negative feedback. Of the limited number of human fMRI studies focusing on the habenula, only one specifically addressed reward. In that study, a juice reward paradigm previously used in monkey studies of the habenula was employed. Juice was used as a reward and delay of expected juice was used as a disappointing stimulus. As in the monkey studies, the human habenula is activated following non-delivery of expected juice reward (Salas et al., 2010). A related study by Ide and Li (2011) used fMRI connectivity analysis to study humans performing a stop signal task in which subjects had to rapidly follow the instruction of "go" or "stop." Each "stop" event could be successful (the prompt called for a "stop") or failed (the prompt indicated "go" when the participant stopped). The investigators looked for regions with larger psychophysiological interaction with the habenula during stop-error than during stop-success trials and identified task-specific activation of the VTA/SNc, internal segment of globus pallidus, bilateral amygdala, and insula. Using Granger causality and mediation analyses they showed a directional link between habenula and VTA/SNc fMRI activation. These results suggest that habenular activity results in a decrease in VTA/SNc activity (Ide and Li, 2011). Finally, there are two reports linking the habenula to human MDD. In a PET 
study, Morris et al. (1999) observed increased coupling between habenula/raphe nucleuses following tryptophan depletion in former MDD patients exhibiting signs of remission. This increase in habenular/raphe coupling correlated with the re-appearance of depression symptoms (Morris et al., 1999). Anatomically, Savitz et al. (2011) presented evidence for a reduction in habenular volume in non-medicated, depressed bipolar disorder patients and female MDD patients.

\section{CONCLUSION}

Much of the work linking the habenula to drug addiction is based on studies of nicotine and nicotinic receptors in the MHb. Additional studies have linked the habenula to morphine and cocaine addiction and withdrawal. Importantly, deep brain stimulation of the habenula has been shown to decrease cocaine-seeking behavior in rodents, which may open the door to possible therapies against cocaine abuse. A caveat to this approach is that cocaine and other drugs of abuse are known to cause degeneration of the fasciculus retroflexus, the primary habenular output, potentially reducing the effectiveness of deep brain stimulation as a treatment for drug abuse. Similarly, nicotine causes degeneration of the internal component of the fasciculus retroflexus, which connects the MHb to the IPN. As a result of this "weak link" between the habenula and downstream structures, the IPN and the RMTg may be more effective primary targets for anti-addiction drugs. Additional research is required to better understand the role of the $\mathrm{MHb}$ and the LHb in drug addiction and to illuminate the relationship between the habenula and downstream structures in the face of addiction. Promising technological advances, such as the use of 7T MRI scanners, may soon allow researchers to differentiate the roles of the $\mathrm{MHb}$ and the LHb in humans with drug addiction, depression, and other disorders (Strotmann et al., 2013). The habenula is a worthy target for study in that it has been shown to play a role in addiction, depression, and negative feedback and negative prediction error events (likely two manifestations of the same phenomenon). The habenula also acts as a major regulator of several neurotransmitter systems, including dopamine, serotonin, norepinephrine, and acetylcholine. These neurotransmitters alter neural activity throughout the brain and thus have the potential to influence a wide-range of both normal and abnormal human behaviors.

\section{ACKNOWLEDGMENTS}

NIDA (026539, 09167); McNair Medical Institute, The Brain and Behavior Foundation.

\section{REFERENCES}

Amos, C. I. (2007). Successful design and conduct of genome-wide association studies. Hum. Mol. Genet. 16(Spec. No. 2), R220-R225. doi: 10.1093/ hmg/ddm 161

Amos, C. I., Wu, X., Broderick, P., Gorlov, I. P., Gu, J., Eisen, T., et al. (2008). Genome-wide association scan of tag SNPs identifies a susceptibility locus for lung cancer at 15q25.1. Nat. Genet. 40, 616-622. doi: 10.1038/ng.109

Bailey, C. D., De Biasi, M., Fletcher, P. J., and Lambe, E. K. (2010). The nicotinic acetylcholine receptor alpha5 subunit plays a key role in attention circuitry and accuracy. J. Neurosci. 30, 9241-9252. doi: 10.1523/JNEUROSCI. $2258-10.2010$
Balcita-Pedicino, J. J., Omelchenko, N., Bell, R., and Sesack, S. R. (2011). The inhibitory influence of the lateral habenula on midbrain dopamine cells: ultrastructural evidence for indirect mediation via the rostromedial mesopontine tegmental nucleus. J. Comp. Neurol. 519, 1143-1164. doi: 10.1002/cne.22561

Berrettini, W., Yuan, X., Tozzi, F., Song, K., Francks, C., Chilcoat, H., et al. (2008). Alpha-5/alpha-3 nicotinic receptor subunit alleles increase risk for heavy smoking. Mol. Psychiatry 13, 368-373. doi: 10.1038/sj.mp.4002154

Bierut, L. J. (2011). Genetic vulnerability and susceptibility to substance dependence. Neuron 69, 618-627. doi: 10.1016/j.neuron.2011.02.015

Bierut, L. J., Stitzel, J. A., Wang, J. C., Hinrichs, A. L., Grucza, R. A., Xuei, X., et al. (2008). Variants in nicotinic receptors and risk for nicotine dependence. Am. J. Psychiatry 165, 1163-1171. doi: 10.1176/appi.ajp.2008.07111711

Broide, R. S., Salas, R., Ji, D., Paylor, R., Patrick, J. W., Dani, J. A., et al. (2002). Increased sensitivity to nicotine-induced seizures in mice expressing the L250T alpha 7 nicotinic acetylcholine receptor mutation. Mol. Pharmacol. 61, 695-705. doi: 10.1124/mol.61.3.695

Brown, R. M., Short, J. L., and Lawrence, A. J. (2010). Identification of brain nuclei implicated in cocaine-primed reinstatement of conditioned place preference: a behaviour dissociable from sensitization. PLOS ONE 5:e15889. doi: 10.1371/journal.pone.0015889

Brunzell, D. H. (2012). Preclinical evidence that activation of mesolimbic alpha 6 subunit containing nicotinic acetylcholine receptors supports nicotine addiction phenotype. Nicotine Tob. Res. 14, 1258-1269. doi: 10.1093/ntr/nts089

Callesen, M. B., Scheel-Krüger, J., Kringelbach, M. L., and Møller, A. (2013). A systematic review of impulse control disorders in Parkinson's disease. J. Parkinsons Dis. 3, 105-138. doi: 10.3233/JPD-120165

Cappendijk, S. L., and Dzoljic, M. R. (1993). Inhibitory effects of ibogaine on cocaine self-administration in rats. Eur. J. Pharmacol. 241, 261-265. doi: 10.1016/00142999(93)90212-Z

Chatterjee, S., Steensland, P., Simms, J. A., Holgate, J., Coe, J. W., Hurst, R. S., etal. (2011). Partial agonists of the alpha3beta ${ }^{*}$ neuronal nicotinic acetylcholine receptor reduce ethanol consumption and seeking in rats. Neuropsychopharmacology 36, 603-615. doi: 10.1038/npp.2010.191

Ciani, E., Severi, S., Bartesaghi, R., and Contestabile, A. (2005). Neurochemical correlates of nicotine neurotoxicity on rat habenulo-interpeduncular cholinergic neurons. Neurotoxicology 26, 467-474. doi: 10.1016/j.neuro.2005.04.001

Coe, J. W., Brooks, P. R., Vetelino, M. G., Wirtz, M. C., Arnold, E. P., Huang, J., et al. (2005). Varenicline: an alpha4beta2 nicotinic receptor partial agonist for smoking cessation. J. Med. Chem. 48, 3474-3477. doi: 10.1021/jm050069n

Crunelle, C. L., Miller, M. L., Booij, J., and van den Brink, W. (2010). The nicotinic acetylcholine receptor partial agonist varenicline and the treatment of drug dependence: a review. Eur. Neuropsychopharmacol. 20, 69-79. doi: 10.1016/j.euroneuro.2009.11.001

Cuello, A. C., Emson, P. C., Paxinos, G., and Jessell, T. (1978). Substance P containing and cholinergic projections from the habenula. Brain Res. 149, 413-429. doi: 10.1016/0006-8993(78)90484-5

Cui, C., Booker, T. K., Allen, R. S., Grady, S. R., Whiteaker, P., Marks, M. J., et al. (2003). The beta3 nicotinic receptor subunit: a component of alpha-conotoxin MII-binding nicotinic acetylcholine receptors that modulate dopamine release and related behaviors. J. Neurosci. 23, 11045-11053.

Di Chiara, G., and Imperato, A. (1988). Drugs abused by humans preferentially increase synaptic dopamine concentrations in the mesolimbic system of freely moving rats. Proc. Natl. Acad. Sci. U.S.A. 85, 5274-5278. doi: 10.1073/pnas.85.14.5274

Ellison, G. (1992). Continuous amphetamine and cocaine have similar neurotoxic effects in lateral habenular nucleus and fasciculus retroflexus. Brain Res. 598, 353-356. doi: 10.1016/0006-8993(92)90207-P

Ellison, G. (2002). Neural degeneration following chronic stimulant abuse reveals a weak link in brain, fasciculus retroflexus, implying the loss of forebrain control circuitry. Eur. Neuropsychopharmacol. 12, 287-297. doi: 10.1016/S0924977X(02)00020-2

Ettenberg, A., Raven, M. A., Danluck, D. A., and Necessary, B. D. (1999). Evidence for opponent-process actions of intravenous cocaine. Pharmacol. Biochem. Behav. 64, 507-512. doi: 10.1016/S0091-3057(99)00109-4

Fonck, C., Cohen, B. N., Nashmi, R., Whiteaker, P., Wagenaar, D. A., RodriguesPinguet, N., et al. (2005). Novel seizure phenotype and sleep disruptions in knockin mice with hypersensitive alpha $4 *$ nicotinic receptors. J. Neurosci. 25, 1139611411. doi: 10.1523/JNEUROSCI.3597-05.2005 
Fowler, C. D., Lu, Q., Johnson, P. M., Marks, M. J., and Kenny, P. J. (2011). Habenular alpha5 nicotinic receptor subunit signalling controls nicotine intake. Nature 471, 597-601. doi: 10.1038/nature09797

Frahm, S., Slimak, M. A., Ferrarese, L., Santos-Torres, J., Antolin-Fontes, B., Auer, S., et al. (2011). Aversion to nicotine is regulated by the balanced activity of beta 4 and alpha5 nicotinic receptor subunits in the medial habenula. Neuron 70, 522-535. doi: 10.1016/j.neuron.2011.04.013

Franceschini, D., Paylor, R., Broide, R., Salas, R., Bassetto, L., Gotti, C., et al. (2002) Absence of alpha7-containing neuronal nicotinic acetylcholine receptors does not prevent nicotine-induced seizures. Brain Res. Mol. Brain Res. 98, 29-40. doi: 10.1016/S0169-328X(01)00309-6

Freedman, R. (2014). $\alpha 7$-nicotinic acetylcholine receptor agonists for cognitive enhancement in schizophrenia. Annu. Rev. Med. 65, 245-261. doi: 10.1146/annurev-med-092112-142937

Friedman, A., Lax, E., Dikshtein, Y., Abraham, L., Flaumenhaft, Y., Sudai, E., et al. (2010). Electrical stimulation of the lateral habenula produces enduring inhibitory effect on cocaine seeking behavior. Neuropharmacology 59, 452-459. doi: 10.1016/j.neuropharm.2010.06.008

Glick, S. D., Maisonneuve, I. M., and Szumlinski, K. K. (2000). 18Methoxycoronaridine (18-MC) and ibogaine: comparison of antiaddictive efficacy, toxicity, and mechanisms of action. Ann. N. Y. Acad. Sci. 914, 369-386. doi: 10.1111/j.1749-6632.2000.tb05211.x

Glick, S. D., Ramirez, R. L., Livi, J. M., and Maisonneuve, I. M. (2006). 18-Methoxycoronaridine acts in the medial habenula and/or interpeduncular nucleus to decrease morphine self-administration in rats. Eur. J. Pharmacol. 537, 94-98. doi: 10.1016/j.ejphar.2006.03.045

Glick, S. D., Rossman, K., Steindorf, S., Maisonneuve, I. M., and Carlson, J. N (1991). Effects and aftereffects of ibogaine on morphine self-administration in rats. Eur. J. Pharmacol. 195, 341-345. doi: 10.1016/0014-2999(91) 90474-5

Gorlich, A., Antolin-Fontes, B., Ables, J. L., Frahm, S., Slimak, M. A., Dougherty, J. D., et al. (2013). Reexposure to nicotine during withdrawal increases the pacemaking activity of cholinergic habenular neurons. Proc. Natl. Acad. Sci. U.S.A. 110, 1707717082. doi: $10.1073 /$ pnas. 1313103110

Groenewegen, H. J., Ahlenius, S., Haber, S. N., Kowall, N. W., and Nauta, W. J. (1986). Cytoarchitecture, fiber connections, and some histochemical aspects of the interpeduncular nucleus in the rat. J. Comp. Neurol. 249, 65-102. doi: 10.1002/cne.902490107

Grucza, R. A., Wang, J. C., Stitzel, J. A., Hinrichs, A. L., Saccone, S. F., Saccone, N. L., et al. (2008). A risk allele for nicotine dependence in CHRNA5 is a protective allele for cocaine dependence. Biol. Psychiatry 64, 922-929. doi: 10.1016/j.biopsych.2008.04.018

Guillem, K., and Peoples, L. L. (2010). Varenicline effects on cocaine self administration and reinstatement behavior. Behav. Pharmacol. 21, 96-103. doi 10.1097/FBP.0b013e328336e9c5

Hall, F. S., Drgonova, J., Jain, S., and Uhl, G. R. (2013). Implications of genome wide association studies for addiction: are our a priori assumptions all wrong? Pharmacol. Ther. 140, 267-279. doi: 10.1016/j.pharmthera.2013.07.006

Hamill, G. S., Olschowka, J. A., Lenn, N. J., Jacobowitz, D. M. (1984). The subnuclear distribution of substance $\mathrm{P}$, cholecystokinin, vasoactive intestinal peptide, somatostatin, leu-enkephalin, dopamine-beta-hydroxylase, and serotonin in the rat interpeduncular nucleus. J. Comp. Neurol. 226, 580-596. doi: 10.1002/cne. 902260410

Heldt, S. A., and Ressler, K. J. (2006). Lesions of the habenula produce stress- and dopamine-dependent alterations in prepulse inhibition and locomotion. Brain Res. 1073-1074, 229-239. doi: 10.1016/j.brainres.2005.12.053

Herkenham, M. (1981). Anesthetics and the habenulo-interpeduncular system: selective sparing of metabolic activity. Brain Res. 210, 461-466. doi: 10.1016/0006-8993(81)90927-6

Herkenham, M., and Nauta, W. J. (1977). Afferent connections of the habenular nuclei in the rat. A horseradish peroxidase study, with a note on the fiber-of-passage problem. J. Comp. Neurol. 173, 123-146. doi: 10.1002/cne.901 730107

Herkenham, M., and Nauta, W. J. (1979). Efferent connections of the habenular nuclei in the rat. J. Comp. Neurol. 187, 19-47. doi: 10.1002/cne.901870103

Hikosaka, O., Sesack, S. R., Lecourtier, L., and Shepard, P. D. (2008). Habenula: crossroad between the basal ganglia and the limbic system. J. Neurosci. 28, 1182511829. doi: 10.1523/JNEUROSCI.3463-08.2008
Hogg, R. C., Raggenbass, M., and Bertrand, D. (2003). Nicotinic acetylcholine receptors: from structure to brain function. Rev. Physiol. Biochem. Pharmacol. 147, 1-46. doi: 10.1007/s10254-003-0005-1

Hsu, Y. W., Tempest, L., Quina, L. A., Wei, A. D., Zeng, H., and Turner, E. E. (2013) Medial habenula output circuit mediated by alpha5 nicotinic receptor-expressing GABAergic neurons in the interpeduncular nucleus. J. Neurosci. 33, 18022-18035. doi: 10.1523/JNEUROSCI.2927-13.2013

Ide, J. S., and Li, C. S. (2011). Error-related functional connectivity of the habenula in humans. Front. Hum. Neurosci. 5:25. doi: 10.3389/fnhum.2011.00025

James, M. H., Charnley, J. L., Flynn, J. R., Smith, D. W., and Dayas, C. V. (2011). Propensity to 'relapse' following exposure to cocaine cues is associated with the recruitment of specific thalamic and epithalamic nuclei. Neuroscience 199, 235242. doi: 10.1016/j.neuroscience.2011.09.047

Jhou, T. C., Fields, H. L., Baxter, M. G., Saper, C. B., and Holland, P. C. (2009a) The rostromedial tegmental nucleus (RMTg), a GABAergic afferent to midbrain dopamine neurons, encodes aversive stimuli and inhibits motor responses. Neuron 61, 786-800. doi: 10.1016/j.neuron.2009.02.001

Jhou, T. C., Geisler, S., Marinelli, M., Degarmo, B. A., and Zahm, D. S. (2009b). The mesopontine rostromedial tegmental nucleus: a structure targeted by the lateral habenula that projects to the ventral tegmental area of Tsai and substantia nigra compacta. J. Comp. Neurol. 513, 566-596. doi: 10.1002/cne.21891

Jhou, T. C., Good, C. H., Rowley, C. S., Xu, S. P., Wang, H., Burnham, N. W., et al. (2013). Cocaine drives aversive conditioning via delayed activation of dopamineresponsive habenular and midbrain pathways. J. Neurosci. 33, 7501-7512. doi: 10.1523/JNEUROSCI.3634-12.2013

Karkowski, L. M., Prescott, C. A., and Kendler, K. S. (2000). Multivariate assessment of factors influencing illicit substance use in twins from female-female pairs. Am. J. Med. Genet. 96, 665-670. doi: 10.1002/1096-8628(20001009)96:5<665::AIDAJMG13>3.0.CO;2-O

Kedmi, M., Beaudet, A. L., and Orr-Urtreger, A. (2004). Mice lacking neuronal nicotinic acetylcholine receptor beta4-subunit and mice lacking both alpha5and beta4-subunits are highly resistant to nicotine-induced seizures. Physiol. Genomics 17, 221-229. doi: 10.1152/physiolgenomics.00202.2003

Kendler, K. S., Karkowski, L. M., Neale, M. C., and Prescott, C. A. (2000). Illicit psychoactive substance use, heavy use, abuse, and dependence in a US population-based sample of male twins. Arch. Gen. Psychiatry 57, 261-269. doi: 10.1001/archpsyc.57.3.261

Kim, U., and Chang, S. Y. (2005). Dendritic morphology, local circuitry, and intrinsic electrophysiology of neurons in the rat medial and lateral habenular nuclei of the epithalamus. J. Comp. Neurol. 483, 236-250. doi: 10.1002/cne.20410

Kimes, A. S., Bell, J. A., and London, E. D. (1990). Clonidine attenuates increased brain glucose metabolism during naloxone-precipitated morphine withdrawal. Neuroscience 34, 633-644. doi: 10.1016/0306-4522(90)90170-9

Klemm, W. R. (2004). Habenular and interpeduncularis nuclei: shared components in multiple-function networks. Med. Sci. Monit. 10, RA261-RA273.

Lax, E., Friedman, A., Croitoru, O., Sudai, E., Ben-Moshe, H., Redlus, L., et al. (2013). Neurodegeneration of lateral habenula efferent fibers after intermittent cocaine administration: implications for deep brain stimulation. Neuropharmacology 75, 246-254. doi: 10.1016/j.neuropharm.2013.06.034

Li, B., Piriz, J., Mirrione, M., Chung, C., Proulx, C. D., Schulz, D., et al. (2011). Synaptic potentiation onto habenula neurons in the learned helplessness model of depression. Nature 470, 535-539. doi: 10.1038/nature09742

Lisoprawski, A., Herve, D., Blanc, G., Glowinski, J., and Tassin, J. P. (1980). Selective activation of the mesocortico-frontal dopaminergic neurons induced by lesion of the habenula in the rat. Brain Res. 183, 229-234. doi: 10.1016/00068993(80)90135-3

Lotfipour, S., Byun, J. S., Leach, P., Fowler, C. D., Murphy, N. P., Kenny, P. J., etal. (2013). Targeted deletion of the mouse alpha2 nicotinic acetylcholine receptor subunit gene (Chrna2) potentiates nicotinemodulated behaviors. J. Neurosci. 33, 7728-7741. doi: 10.1523/JNEUROSCI. 4731-12.2013

Madsen, H. B., Brown, R. M., Short, J. L., and Lawrence, A. J. (2012). Investigation of the neuroanatomical substrates of reward seeking following protracted abstinence in mice. J. Physiol. 590(Pt 10), 2427-2442. doi: 10.1113/jphysiol.2011. 225219

Maisonneuve, I. M., and Glick, S. D. (2003). Anti-addictive actions of an iboga alkaloid congener: a novel mechanism for a novel treatment. Pharmacol. Biochem. Behav. 75, 607-618. doi: 10.1016/S0091-3057(03)00119-9 
Maroteaux, M., and Mameli, M. (2012). Cocaine evokes projection-specific synaptic plasticity of lateral habenula neurons. J. Neurosci. 32, 12641-12646. doi: 10.1523/JNEUROSCI.2405-12.2012

Maskos, U., Molles, B. E., Pons, S., Besson, M., Guiard, B. P., Guilloux, J. P., et al. (2005). Nicotine reinforcement and cognition restored by targeted expression of nicotinic receptors. Nature 436, 103-107. doi: 10.1038/nature03694

Matsumoto, M., and Hikosaka, O. (2007). Lateral habenula as a source of negative reward signals in dopamine neurons. Nature 447, 1111-1115. doi: 10.1038 /nature 05860

Mayberg, H. S. (2009). Targeted electrode-based modulation of neural circuits for depression. J. Clin. Invest. 119, 717-725. doi: 10.1172/JCI38454

McCallum, S. E., Cowe, M. A., Lewis, S. W., and Glick, S. D. (2012). $\alpha 3 \beta 4$ nicotinic acetylcholine receptors in the medial habenula modulate the mesolimbic dopaminergic response to acute nicotine in vivo. Neuropharmacology 63, 434-440. doi: 10.1016/j.neuropharm.2012.04.015

McCallum, S. E., and Glick, S. D. (2009). 18-Methoxycoronaridine blocks acquisition but enhances reinstatement of a cocaine place preference. Neurosci. Lett. 458 57-59. doi: 10.1016/j.neulet.2009.04.019

Mihalak, K. B., Carroll, F. I., and Luetje, C. W. (2006). Varenicline is a partial agonis at alpha4beta2 and a full agonist at alpha7 neuronal nicotinic receptors. Mol Pharmacol. 70, 801-805. doi: 10.1124/mol.106.025130

Mohanakumar, K. P., and Sood, P. P. (1983). Acetylcholinesterase changes in the central nervous system of mice during the development of morphine tolerance addiction and withdrawal. Brain Res. Bull. 10, 589-596. doi: 10.1016/03619230(83)90026-6

Montague, P. R., Dayan, P., and Sejnowski, T. J. (1996). A framework for mesencephalic dopamine systems based on predictive Hebbian learning. J. Neurosci. 16 1936-1947.

Morel, C., Fattore, L., Pons, S., Hay, Y. A., Marti, F., Lambolez, B., et al. (2013). Nicotine consumption is regulated by a human polymorphism in dopamine neurons. Mol. Psychiatry doi: 10.1038/mp.2013.158 [Epub ahead of print].

Morris, J. S., Smith, K. A., Cowen, P. J., Friston, K. J., and Dolan, R. J. (1999). Covariation of activity in habenula and dorsal raphe nuclei following tryptophan depletion. Neuroimage 10, 163-172. doi: 10.1006/nimg. 1999.0455

Neugebauer, N. M., Einstein, E. B., Lopez, M. B., McClure-Begley, T. D., Mineur, Y. S., and Picciotto, M. R. (2013). Morphine dependence and withdrawal induced changes in cholinergic signaling. Pharmacol. Biochem. Behav. 109, 77-83. doi: 10.1016/j.pbb.2013.04.015

Panchal, V., Taraschenko, O. D., Maisonneuve, I. M., and Glick, S. D. (2005). Attenuation of morphine withdrawal signs by intracerebral administration of 18-methoxycoronaridine. Eur. J. Pharmacol. 525, 98-104. doi: 10.1016/j.ejphar.2005.09.060

Picciotto, M. R., Zoli, M., Rimondini, R., Léna, C., Marubio, L. M., Pich, E. M., et al. (1998). Acetylcholine receptors containing the beta2 subunit are involved in the reinforcing properties of nicotine. Nature 391, 173-177. doi: $10.1038 / 34413$

Quick, M. W., Ceballos, R. M., Kasten, M., McIntosh, J. M., and Lester, R. A. (1999). $\alpha 3 \beta 4$ subunit-containing nicotinic receptors dominate function in rat medial habenula neurons. Neuropharmacology 38, 769-783. doi: 10.1016/S00283908(99)00024-6

Rezvani, A. H., Overstreet, D. H., and Lee, Y. W. (1995). Attenuation of alcohol intake by ibogaine in three strains of alcohol-preferring rats. Pharmacol. Biochem. Behav. 52, 615-620. doi: 10.1016/0091-3057(95)00152-M

Salas, R., Baldwin, P., de Biasi, M., and Montague, P. R. (2010). BOLD responses to negative reward prediction errors in human habenula. Front. Hum. Neurosci. 4:36. doi: 10.3389/fnhum.2010.00036

Salas, R., Orr-Urtreger, A., Broide, R. S., Beaudet, A., Paylor, R., and De Biasi, M. (2003a). The nicotinic acetylcholine receptor subunit alpha 5 mediates short-term effects of nicotine in vivo. Mol. Pharmacol. 63, 1059-1066. doi: 10.1124/mol.63.5.1059

Salas, R., Pieri, F., Fung, B., Dani, J. A., and De Biasi, M. (2003b). Altered anxietyrelated responses in mutant mice lacking the beta4 subunit of the nicotinic receptor. J. Neurosci. 23, 6255-6263.

Salas, R., Cook, K. D., Bassetto, L., and De Biasi, M. (2004a). The alpha3 and beta 4 nicotinic acetylcholine receptor subunits are necessary for nicotine-induced seizures and hypolocomotion in mice. Neuropharmacology 47, 401-407. doi: 10.1016/j.neuropharm.2004.05.002
Salas, R., Pieri, F., and De Biasi, M. (2004b). Decreased signs of nicotine withdrawal in mice null for the beta4 nicotinic acetylcholine receptor subunit. J. Neurosci. 24, 10035-10039. doi: 10.1523/JNEUROSCI.1939-04.2004

Salas, R., Sturm, R., Boulter, J., and De Biasi, M. (2009). Nicotinic receptors in the habenulo-interpeduncular system are necessary for nicotine withdrawal in mice. J. Neurosci. 29, 3014-3018. doi: 10.1523/JNEUROSCI. 4934-08.2009

Sartorius, A., Kiening, K. L., Kirsch, P., von Gall, C. C., Haberkorn, U., Unterberg, A. W., et al. (2010). Remission of major depression under deep brain stimulation of the lateral habenula in a therapy-refractory patient. Biol. Psychiatry 67, e9-e11. doi: 10.1016/j.biopsych.2009.08.027

Savitz, J. B., Nugent, A. C., Bogers, W., Roiser, J. P., Bain, E. E., Neumeister, A., et al. (2011). Habenula volume in bipolar disorder and major depressive disorder: a high-resolution magnetic resonance imaging study. Biol. Psychiatry 69, 336-343. doi: 10.1016/j.biopsych.2010.09.027

Schultz, W., Dayan, P., and Montague, P. R. (1997). A neural substrate of prediction and reward. Science 275, 1593-1599. doi: 10.1126/science.275.5306.1593

Shepard, P. D., Holcomb, H. H., and Gold, J. M. (2006). Schizophrenia in translation: the presence of absence: habenular regulation of dopamine neurons and the encoding of negative outcomes. Schizophr. Bull. 32, 417-421. doi: $10.1093 /$ schbul/sbj083

Shumake, J., Conejo-Jimenez, N., Gonzalez-Pardo, H., and Gonzalez-Lima, F. (2004). Brain differences in newborn rats predisposed to helpless and depressive behavior. Brain Res. 1030, 267-276. doi: 10.1016/j.brainres.2004.10.015

Steensland, P., Simms, J. A., Holgate, J., Richards, J. K., and Bartlett, S. E. (2007) Varenicline, an alpha4beta2 nicotinic acetylcholine receptor partial agonist, selectively decreases ethanol consumption and seeking. Proc. Natl. Acad. Sci. U.S.A. 104, 12518-12523. doi: 10.1073/pnas.0705368104

Stern, W. C., Johnson, A., Bronzino, J. D., and Morgane, P. J. (1981). Neuropharmacology of the afferent projections from the lateral habenula and substantia nigra to the anterior raphe in the rat. Neuropharmacology 20, 979-989. doi: 10.1016/0028-3908(81)90029-0

Strotmann, B., Heidemann, R. M., Anwander, A., Weiss, M., Trampel, R., Villringer, A., et al. (2013). High-resolution MRI and diffusion-weighted imaging of the human habenula at 7 tesla. J. Magn. Reson. Imaging doi: 10.1002/jmri.24252 [Epub ahead of print].

Tapper, A. R., McKinney, S. L., Nashmi, R., Schwarz, J., Deshpande, P., Labarca, C., et al. (2004). Nicotine activation of alpha4* receptors: sufficient for reward, tolerance, and sensitization. Science 306, 1029-1032. doi: 10.1126/science.1099420

Taraschenko, O. D., Shulan, J. M., Maisonneuve, I. M., and Glick, S. D. (2007). $18-\mathrm{MC}$ acts in the medial habenula and interpeduncular nucleus to attenuate dopamine sensitization to morphine in the nucleus accumbens. Synapse 61, 547560. doi: 10.1002/syn.20396

Thorgeirsson, T. E., Geller, F., Sulem, P., Rafnar, T., Wiste, A., Magnusson, K. P., et al. (2008). A variant associated with nicotine dependence, lung cancer and peripheral arterial disease. Nature 452, 638-642. doi: 10.1038/nature06846

Tsuang, M. T., Lyons, M. J., Meyer, J. M., Doyle, T., Eisen, S. A., Goldberg, J., et al. (1998). Co-occurrence of abuse of different drugs in men: the role of drug-specific and shared vulnerabilities. Arch. Gen. Psychiatry 55, 967-972. doi: 10.1001/archpsyc.55.11.967

Ullsperger, M., and von Cramon, D. Y. (2003). Error monitoring using external feedback: specific roles of the habenular complex, the reward system, and the cingulate motor area revealed by functional magnetic resonance imaging. J. Neurosci. 23, 4308-4314.

Wada, E., Wada, K., Boulter, J., Deneris, E., Heinemann, S., Patrick, J., et al. (1989). Distribution of alpha 2, alpha 3, alpha 4, and beta 2 neuronal nicotinic receptor subunit mRNAs in the central nervous system: a hybridization histochemical study in the rat. J. Comp. Neurol. 284, 314-335. doi: 10.1002/cne. 902840212

Wang, J. C., Grucza, R., Cruchaga, C., Hinrichs, A. L., Bertelsen, S., Budde, J. P., et al. (2009). Genetic variation in the CHRNA5 gene affects mRNA levels and is associated with risk for alcohol dependence. Mol. Psychiatry 14, 501-510. doi: 10.1038/mp.2008.42

Wang, R. Y., and Aghajanian, G. K. (1977). Physiological evidence for habenula as major link between forebrain and midbrain raphe. Science 197, 89-91. doi: 10.1126/science. 194312

Wang, Y., Lee, J. W., Oh, G., Grady, S. R., McIntosh, J. M., Brunzell, D. H., et al. (2013). Enhanced synthesis and release of dopamine in transgenic mice with 
gain-of-function alpha6* nAChRs. J. Neurochem. doi: 10.1111/jnc.12616 [Epub ahead of print].

$\mathrm{Xu}$, W., Gelber, S., Orr-Urtreger, A., Armstrong, D., Lewis, R. A., $\mathrm{Ou}$, C. N., etal. (1999a). Megacystis, mydriasis, and ion channel defect in mice lacking the alpha3 neuronal nicotinic acetylcholine receptor. Proc. Natl. Acad. Sci. U.S.A. 96, 5746-5751. doi: 10.1073/pnas.96.10. 5746

Xu, W., Orr-Urtreger, A., Nigro, F., Gelber, S., Sutcliffe, C. B., Armstrong, D., et al. (1999b). Multiorgan autonomic dysfunction in mice lacking the beta2 and the beta4 subunits of neuronal nicotinic acetylcholine receptors. J. Neurosci. 19, 9298-9305.

Young, J. W., and Geyer, M. A. (2013). Evaluating the role of the alpha-7 nicotinic acetylcholine receptor in the pathophysiology and treatment of schizophrenia. Biochem. Pharmacol. 86, 1122-1132. doi: 10.1016/j.bcp.2013.06.031
Conflict of Interest Statement: The authors declare that the research was conducted in the absence of any commercial or financial relationships that could be construed as a potential conflict of interest.

Received: 25 October 2013; accepted: 09 March 2014; published online: 28 March 2014. Citation: Velasquez KM, Molfese DL and Salas R (2014) The role of the habenula in drug addiction. Front. Hum. Neurosci. 8:174. doi: 10.3389/fnhum.2014.00174

This article was submitted to the journal Frontiers in Human Neuroscience.

Copyright (C) 2014 Velasquez, Molfese and Salas. This is an open-access article distributed under the terms of the Creative Commons Attribution License (CC BY). The use, distribution or reproduction in other forums is permitted, provided the original author(s) or licensor are credited and that the original publication in this journal is cited, in accordance with accepted academic practice. No use, distribution or reproduction is permitted which does not comply with these terms. 